\title{
Impact of hysterectomy on uterine cancer incidence rates in Egypt
}

\begin{abstract}
Background: Uterine cancer is one of the common women's cancers worldwide. There are significant variations in uterine cancer incidence rates globally and the incidence in Egypt is one of the lowest. Several studies have shown that hysterectomy might be a factor in underestimating the observed incidence of uterine cancer. However, no studies have been conducted in Egypt to examine this observation.
\end{abstract}

Methods: Pathologic reports of all 1040 hysterectomy specimens examined in 2013 and 2014 in the Gharbiah province, Egypt were abstracted. Prevalence of hysterectomy was estimated and used for adjusting the incidence rate of uterine cancer in the Gharbiah population-based registry by excluding the hysterectomized women from the population at risk. Pre- and post- adjustment rates were compared and $95 \%$ confidence intervals (CIs) were calculated.

Results: The prevalence of hysterectomy was estimated as 13.1 per 10,000 women, $95 \% \mathrm{CI}$ (12.65-13.66). The prevalence of hysterectomy did not have a significant impact on uterine cancer incidence [pre-adjustment $(2.78,95 \%$ CI 2.58-3.00) and post-adjustment (2.79, $95 \%$ CI 2.58-3.00)]. Observing a significant effect of hysterectomy on underestimating the incidence of uterine cancer in this population required multiplying the observed prevalence by at least 110 times.

Discussion: This study confirmed the previously documented low incidence of uterine cancer in this population of Egypt. The lack of evidence about the possible role of hysterectomy in lowering uterine cancer incidence justifies the need for additional research to identify the protective factors for uterine cancer in this population.

Keywords: uterine cancer, hysterectomy prevalence, epidemiology, Egypt, developing countries
Volume I2 Issue I - 202I

Saad Alshahrani MD PhD,' Robert M

Chamberlain, PhD, ${ }^{2,3}$ Ahmed Hablas MD, ${ }^{4}$

Steven Remmenga MD, ${ }^{5}$ Jane L Meza, ${ }^{6}$

Ibrahim A Seifeldin MD, ${ }^{4}$ Mohamed Ramadan

$\mathrm{MD},{ }^{4}$ Mariah Murray MPH, ${ }^{7}$ Amr S Soliman

$\mathrm{MDPhD} \mathrm{Ph}^{3}$

'Department of Epidemiology, King Fahad Specialist Hospital, Saudi Arabia

${ }^{2}$ Department of Epidemiology, University of Texas, M.D.

Anderson Cancer Center, USA

${ }^{3}$ Department of Community Health and Social Medicine, CUNY

School of Medicine, USA

${ }^{4}$ Gharbiah Cancer Society and Gharbiah Cancer Registry, Egypt

${ }^{5}$ Department of Obstetrics and Gynecology, University of

Nebraska Medical Center, USA

${ }^{6}$ Department of Biostatistics, College of Public Health,

University of Nebraska Medical Center, USA

${ }^{7}$ University of Arizona College of Public Health, USA

Correspondence: Amr S. Soliman, MD, Ph.D, Department of Community Health and Social Medicine, CUNY School of Medicine, New York, NY, USA, Tel (2I2) 650-85 I9, Fax (2I2) 650-7778,Email asolima@med.cuny.edu

Received: December 31, 2020 | Published: February 04, 202 |

\section{Background}

Uterine cancer is one of the common cancers affecting women worldwide. ${ }^{1}$ However, there are significant variations in the incidence globally with highest rates in North America (19.1 per 100,000) and lowest rates in Africa (3.5 per 100,000). ${ }^{2}$

The age-standardized incidence rate of uterine cancer in Egypt was reported in 2012 as 3.8 per 100,000 compared to a global average incidence of 8.2 per $100,000 .{ }^{2}$ Uterine cancer is ranked as the tenth most common women's cancer in Egypt. Reports from the Middle East Cancer Consortium (MECC) showed that the incidence rate of uterine cancer in Egypt was the lowest (3.5 per 100,000) compared to rates from other MECC countries in the region: Jordan (5.8 per $100,000)$, Israeli Arabs $(8.7$ per 100,000$)$, Cyprus $(11.8$ per 100,000$)$ and Israeli Jews $(13.8$ per 100,000$){ }^{3}$

In addition to the wide range of geographic variation in uterine cancer incidence rates in the Middle East, underestimation of uterine cancer is suspected in Egypt due to the presumed frequent hysterectomy procedures in the country. ${ }^{4,5}$

Surgical resection of the uterus (hysterectomy) is one of the main lines of surgical treatment of uterine cancer. There are also other medical indications for performing hysterectomy. ${ }^{6}$ These indications include uterine leiomyomas (fibroid), dysfunctional uterine bleeding, endometrial adenomyosis, genital prolapse, chronic pelvic pain, pelvic inflammatory disease, massive postpartum hemorrhages, endometrial hyperplasia and uterine cancers. ${ }^{7}$ The majority of hysterectomies are performed for managing non-malignant conditions and fibroids are considered the most common indication for hysterectomy. ${ }^{8}$ Nonmalignant conditions that were treated by hysterectomy accounted for $88 \%, 81 \%$, and $78 \%$ of all hysterectomy procedures in the US 9 Germany ${ }^{10}$ and Sweden, ${ }^{11}$ respectively.

Hysterectomy is one of the most common gynecologic surgical procedures for women worldwide and has been reported in 2009 as the second most common surgery for women in the U.S. $(479,814$ hysterectomies/year). ${ }^{12}$ The incidence rate of hysterectomy varies across the globe, with reported rates of 510 per 100,000 in the US, ${ }^{13}$ a much lower incidence rate in Europe as demonstrated by an incidence rate of 173 per 100,000 in Denmark. ${ }^{14}$ Unfortunately, Egypt and most of developing countries have a scarcity of research about hysterectomy.

Some studies have shown that hysterectomy might be a factor in underestimating the observed incidence of uterine cancer. It has always been believed that white non-Hispanic women have significantly higher incidence of uterine cancer than the incidence in other racial groups in the U.S. It is interesting to note that the overall age-adjusted endometrial cancer rate increased $66.8 \%$ in all racial groups after correcting for hysterectomy prevalence. ${ }^{15}$ After adjusting for hysterectomy, Blacks had the highest increase in endometrial cancer incidence rate by $95.3 \%$, followed by $65.1 \%$ for White nonHispanics, and $57.6 \%$ for Hispanics. These adjustments provided a better understanding of the actual incidence rates between the different racial groups considering the influence of different hysterectomy rates among them..$^{15}$ Therefore, adjustment for hysterectomy was an important factor in documenting the actual uterine cancer rate in the 
U.S. population. Other studies $10,{ }^{16}$ supporting this finding, reported that the hysterectomy correction has a different effect on the incidence rate of endometrial cancer in different geographical regions of the U.S. For example, the hysterectomy correction had a high impact on rates in Southern U.S. compared to other U.S. regions. ${ }^{17}$

Adjusting for hysterectomy had different levels of effect on the uterine cancer incidence rate depending on the prevalence of hysterectomy in different countries. For example, after adjusting for the prevalence of hysterectomy, uterine cancer incidence rate increased in England and Wales from 13.4 to 16.2 per 100,000, from 15.9 to 23.0 per 100,000 in Germany, and from 14.6 to 18.8 per 100,000 in Finland. ${ }^{18-20}$

In Egypt, there are no clear data about the prevalence of hysterectomy and the indication of this surgery. However, there are clinical impressions about a frequent practice of hysterectomy in the country. Because of the documented low incidence of uterine cancer in Egypt and the presumed high rates of hysterectomy, this is the first study to quantify the impact of hysterectomy rate on the incidence rate of uterine cancer in Gharbiah province of Egypt.

\section{Methods}

\section{Data collection}

The population of the study region: The Gharbiah province is located in the center of the Nile delta region of Egypt in a space area of $1,948 \mathrm{~km}^{2}$ and a population of approximately $4,011,320$. The province is composed of 8 districts: Tanta, Al-Mahallah al-Kubrā, As-Santah, Basyoun, Kafr az-Zayyat, Quțur, Samannūd, and Zefta. The two main districts that encompass the majority of the Gharbiah population and health care facilities are Tanta (TA) and Al-Mahallah Al-kubra (MK). Approximately $50 \%$ of the population lives in TA and MK.

\section{The hysterectomy dataset}

The primary pathology laboratories that examine all uterine specimens in the province were included in this study. The main pathology laboratories in Tanta are located at the Tanta University Medical School, the Gharbiah Cancer Society (GCS), the Menshawy hospital and 3 other private laboratories. In MK and Kafr az-Zayyat, there are 3 private labs that could receive and examine uterine specimens. Patients from the other 6 districts of Gharbiah come to these pathology laboratories, if uterine specimens need histopathologic examination. Based on the Ministry of Health regulations in Egypt, uterine biopsies after every hysterectomy procedure must be sent to pathology laboratories for histopathologic examination before treatment.

All logbooks of the above-listed laboratories in 2013 and 2014 were reviewed. The review was limited to this period since records prior to 2013 were not available because of inadequate storage spaces in the labs. After identifying all uterine biopsies from the logbooks, pathology reports of each case were examined. In Tanta, there were 1055 hysterectomy specimens among 3072 benign uterine lesions. There were 306 hysterectomy specimens identified from 1008 cases of benign uterine lesions in MK. The benign hysterectomy specimens included leiomyomas, endometriosis, endometrial hyperplasia, uterine prolapse, and abnormal uterine bleeding. Samples included in this study represented all patients from all districts of Gharbiah aged $18-80$ years.

Variables abstracted from pathology reports included lab ID number, age, clinical presentation, type of surgery, date of the procedure, pathologic diagnosis, pathology laboratory and district referral surgeon.

The incidence rate of uterine cancer for Gharbiah was calculated using the Gharbiah population-based Cancer Registry (GPCR) for uterine cancer cases available for the period 1999-2010 and the population data from the Central Agency for Public Mobilization and Statistics (CAPMAS) census. ${ }^{21}$

\section{Data management and statistical analysis}

The incidence rate (IR) of hysterectomy (E) was calculated for 2013 and 2014 in the Gharbiah region by dividing the number of newly-diagnosed cases of hysterectomy by the population of women in Gharbiah during the same time period. The $95 \%$ Confidence Interval (CI) was calculated using the following formula: $C I=I R \pm 1.96 \times I R / \sqrt{ } E$.

In order to adjust for the effect of hysterectomy on uterine cancer incidence rates, all women with hysterectomies (prevalent cases) were eliminated from the denominator of at-risk women. Therefore, backward prevalence projection was calculated under the assumption that age has a constant effect pattern and the stability of health carerelated factors (e.g. availability, affordability, accessibility). The hysterectomy probability was derived from the hysterectomy rate by using hysterectomy probability, $q(h)=1-e^{-5 r(h)}$ as used in a previous study from New South Wales of Australia. ${ }^{22}$

Here, $\mathrm{r}(\mathrm{h})$ stands for hysterectomy rate by five year age groups. The 95\% Confidence Interval (CI) for prevalence (P) was calculated using the following formula: $C I=P \pm 1.96 \times(\sqrt{ } P(1-P) / n)$ where (n) stands for the population size. The adjusted uterine cancer rate was calculated by removing the hysterectomized women from the population at risk (denominator). The adjusted uterine cancer incidence rate was compared to the pre-adjustment rate using $95 \%$ confidence intervals. SAS statistical software was used in the analysis (SAS version 9.4 SAS Institute Inc., Cary, NC).

Details of uterine cancer incidence rate calculations are included in our previous publication. ${ }^{23}$ The study was approved by the Institutional Review Board (IRB) at University Nebraska Medical Center (UNMC) and Gharbiah Cancer Center Ethics Committee.

\section{Result}

There were 1040 hysterectomy cases in the Gharbiah region during the period of 2013 and 2014. The total crude incidence rate of hysterectomy was 26.3 per 100,000 women [ $95 \%$ CI (24.7-27.9)]. The age-specific rate of hysterectomy was highest in the age groups (4049 years) and (50-59 years) by rates of 112.2 and 109.7 per 100,000 women, respectively, (Table 1). The age-standardized rate (ASR) of hysterectomy was 30.4 and 95\% CI was (28.5-32.2) per 100,000.

Table I Crude incidence rates of hysterectomy by age groups/100,000, Gharbiah 2013-2014

\begin{tabular}{lllll}
\hline AGE & $\begin{array}{l}\text { Hysterectomy } \\
\text { Cases }\end{array}$ & Incidence Rate & $\mathbf{9 5 \%} \mathbf{C l}$ & \\
\hline$<40$ & 115 & 3.94 & 3.27 & 4.71 \\
$40-49$ & 522 & 112.25 & 102.93 & 122.19 \\
$50-59$ & 346 & 109.67 & 98.56 & 121.68 \\
$60-69$ & 47 & 28.69 & 21.34 & 37.8 \\
$>=70$ & 10 & 10.98 & 5.64 & 19.48 \\
Total & 1040 & 26.3 & 24.74 & 27.93 \\
\hline
\end{tabular}


The estimated prevalence of hysterectomy was 13.1 per 10,000 women and $95 \%$ CI was (12.65-13.66). The age group of $45-49$ years had the highest prevalence of 74.8 per 10,000 women. The prevalence of hysterectomy among women in Gharbiah increased with age to the peak in the age group of 45 to 49 years then gradually decreased in older women (Table 2).

Table 2 Projected prevalence of hysterectomy in the women population of Gharbiah, Egypt 1999-2010

\begin{tabular}{llll}
\hline Age groups & $\begin{array}{l}\text { Hysterectomy prevalence } \\
\text { per } \mathbf{1 0 , 0 0 0}\end{array}$ & $95 \% \mathrm{Cl}$ \\
\hline $15-19$ & 0.1 & 0.03 & 0.36 \\
$20-24$ & 0.1 & 0.04 & 0.37 \\
$25-29$ & 2.1 & 1.54 & 2.92 \\
$30-34$ & 4.6 & 3.54 & 5.87 \\
$35-39$ & 13.8 & 11.95 & 15.94 \\
$40-44$ & 39.3 & 36 & 42.98 \\
$45-49$ & 74.8 & 69.89 & 80.13 \\
$50-54$ & 67.7 & 62.67 & 73.17 \\
$55-59$ & 32 & 27.92 & 36.7 \\
$60-64$ & 16.1 & 12.91 & 20.13 \\
$65-69$ & 18.4 & 14.39 & 23.59 \\
$70-74$ & 6.4 & 3.88 & 10.58 \\
$75+$ & 4.5 & 2.45 & 8.31 \\
Total & 13.1 & 12.65 & 13.66 \\
\hline
\end{tabular}

After adjusting for the hysterectomy cases in the population at risk, the uterine cancer incidence rate was not affected significantly in all age groups. The total crude rate of uterine cancer after adjustment for hysterectomy was 2.79 and $95 \%$ CI $(2.58-300)$ per 100,000 compared to almost the same rate (2.78 per 100,000 women) before the adjustment (Table 3). Moreover, no significant differences were seen for pre- or post-menopausal women regarding crude incidence rates of uterine cancer after adjustment for hysterectomy (Table 4).

Table 3 Uterine cancer incidence rate before and after adjustment for hysterectomy by age group Gharbiah, 1999-2010

\begin{tabular}{lllllllll}
\hline & & \multicolumn{3}{c}{ Before adjustment } & \multicolumn{3}{c}{ After adjustment } \\
\cline { 3 - 3 } & Cases & $\begin{array}{l}\text { Crude } \\
\text { rate }\end{array}$ & $95 \% \mathbf{C l}$ & \multicolumn{2}{l}{ Crude } & $95 \% \mathbf{~ C l}$ \\
\hline$<40$ & 33 & 0.19 & 0.13 & 0.26 & 0.19 & 0.13 & 0.26 \\
$40-49$ & 82 & 2.94 & 2.35 & 3.63 & 2.96 & 2.37 & 3.65 \\
$50-59$ & 237 & 12.52 & 11 & 14.19 & 12.59 & 11.06 & 14.27 \\
$60-69$ & 217 & 22.07 & 19.28 & 25.16 & 22.11 & 19.31 & 25.2 \\
$>=70$ & 91 & 16.65 & 13.49 & 20.34 & 16.66 & 13.5 & 20.36 \\
Total & 660 & 2.78 & 2.58 & 3 & 2.79 & 2.58 & 3 \\
\hline
\end{tabular}

The incidence rate of uterine cancer did not change significantly after adjusting for the projected hysterectomy prevalence [preadjustment $\mathrm{IR}=2.78,95 \% \mathrm{CI}(2.85-3.00)$, post-adjustment $\mathrm{IR}=2.79$ $95 \%$ CI (2.58-3.00)]. The incidence rate of uterine cancer could be significantly impacted to become IR $=3.2595 \%$ CI (3.01-3.51), if the current observed prevalence would increase by 110 times.

Table 4 Uterine cancer crude incidence rate before and after adjustment for hysterectomy by menopausal status, Gharbiah, 1999-2010

\begin{tabular}{llllllll}
\hline & & \multicolumn{3}{c}{ Before adjustment } & \multicolumn{3}{l}{ After adjustment } \\
\cline { 2 - 8 } Menopause & Cases & Crude rate & LL & UL & Crude rate & LL & UL \\
\hline Pre-menopause & II5 & 0.57 & 0.47 & 0.68 & 0.57 & 0.47 & 0.68 \\
Post-menopause & 545 & 15.92 & 14.63 & 17.3 & 15.98 & 14.68 & 17.36 \\
Total & 660 & 2.78 & 2.58 & 3 & 2.79 & 2.58 & 3 \\
\hline
\end{tabular}

\section{Discussion}

This study has revealed interesting findings. First, women in Gharbiah have a low incidence rate of hysterectomy. Second, uterine cancer incidence rates did not change after adjusting for hysterectomy in this population. Third, based on the uterine cancer incidence, the observed uterine hysterectomy prevalence would need to be 110 times the current hysterectomy rate to have a significant impact on the uterine cancer incidence.

This study showed that the crude and ASR of hysterectomy rates in Gharbiah were significantly lower than the respective rates reported from other countries. For example, in the U.S., the ASR of hysterectomy was 500 per 100,000 women in 2000-2004. ${ }^{13}$ In Germany, the ASR of hysterectomy was reported as 362.9 per 100,000-person year in 20052006. ${ }^{10}$ However, other developed countries showed hysterectomy incidence rates of 370 and 120 per 100,000 women in Italy and Norway, respectively. ${ }^{24,25}$ Based on the available data from Africa, the hysterectomy rate was very low compared to rates in developed countries. For example, the hysterectomy incidence rate was 5 per 100,000 women in rural areas of Kenya in $1996,{ }^{26}$ while the ASR of hysterectomy in our study from Egypt is 30.4 per 100,000. The difference between hysterectomy ASRs in developed and developing countries could be attributed to differences in fertility rates as well as variation in availability of health care services and reliability of medical records and disease registries. The highest age-specific rates of hysterectomy in this population were observed in the same age groups of high age-specific rates in developed countries [(40-49 years) and (50-59 years) $]^{27}$

These findings and observations regarding the low incidence of hysterectomy in this population in Egypt were confirmed by the results of our calculation of the prevalence rate to estimate the denominator of at-risk women. For example, the prevalence rate of hysterectomy in this population was $0.13 \%$ compared to prevalence of $6.9 \%$ in rural areas of India and $16.9 \%$ in the U.S. ${ }^{28,29}$ A hospital-based study from Ain Shams University hospital in Cairo showed an increment in admission numbers of patients requiring hysterectomy surgery by comparing hospital admission rates of 1995-1996 to the rate in $2000 .{ }^{4}$ Unfortunately, there is a scarcity of studies of hysterectomy prevalence and incidence in Africa and developing countries, in 
general. Therefore, it is difficult to document changes in hysterectomy trends over time.

Regarding the second observation of insignificant impact of hysterectomy on uterine cancer incidence in this study, previous studies from the U.S. showed that adjustment for hysterectomy prevalence increased the overall age-adjusted endometrial cancer incidence rate from 29.2 per 100,000 to 48.7 per 100,000 i.e. increase in rate by $66.8 \%$ during the period 1992-2000..$^{15}$ Furthermore, several studies found that failure to adjust for hysterectomy prevalence resulted in distortion of uterine cancer rates based on age, race, and place of residence in the United State. ${ }^{10,16,30}$ In Germany, corrected uterine cancer incidence rate after adjusting for hysterectomy prevalence led to a $20 \%$ increase in incidence. ${ }^{31}$ Moreover, hysterectomy prevalence has different impacts on uterine cancer incidence rates among different populations. For example, the relative change in uterine cancer incidence rates after adjusting for hysterectomy prevalence was higher in the U.S. compared to some European countries. ${ }^{31}$ Our study showed that the low prevalence of hysterectomy in this study had no significant impact on uterine cancer incidence rate in Gharbiah, Egypt.

The results of our study revealed that hysterectomy procedures are not as common as presumed based on clinical impressions. The hysterectomy prevalence in our study population was not high enough to influence uterine cancer incidence rate. There are multiple factors that might have contributed to the results. There is a possibility that not all cases of hysterectomy were recorded or reported due to incomplete reporting, inadequate record storage, or illegal undocumented practices. However, the significant impact of hysterectomy on uterine cancer incidence rate in this population did not appear until the observed prevalence was multiplied by 110 . Therefore, it is highly unlikely that even with underreporting of hysterectomy that uterine cancer rate is underestimated in this population.

In addition, there are certain factors that could influence hysterectomy rates, such as availability and affordability of health care facilities and levels of socioeconomic status. ${ }^{32,33}$ Furthermore, knowledge and attitude about hysterectomy influence decisionmaking regarding hysterectomy. A Swiss study found that patients' knowledge about hysterectomy and different alternative treatments could reduce the choice of hysterectomy. ${ }^{34}$ Cultural factors may also lead to acceptance or rejection of hysterectomy as a line of treatment. For example, in the Middle East, the uterus is considered an important organ of femininity and reproduction even in multiparous older women. ${ }^{35,36}$ The beliefs about the importance of the uterus may affect the utilization of hysterectomy among women and may also influence their consideration of other alternative non-surgical lines of treatments such as hormonal manipulation and laser ablation. It is important to note that while hysterectomy rates were shown to be low in this study, the increasing rates of obesity in this population could result in increasing rates of gynecological diseases that require hysterectomy for treatment. $5,37,38$

The study has several strengths. The study was the first populationbased investigation of the influence of hysterectomy on uterine cancer rates in Egypt. The availability of reliable data from the populationbased cancer registry of Egypt on uterine cancer adds to the validity of the information. ${ }^{38}$ The study also provided useful information about the low rate of hysterectomy in this population in Egypt. The low rate of hysterectomy in this population can be extrapolated to the population of women in Egypt, as Gharbiah is representative of the country in terms of the population age structure, socioeconomic, and geographic status. The inclusion of the limited number of pathology laboratories in this study increased the opportunity for capturing the vast majority of the resected hysterectomy specimens during the study period. However, the study has a few limitations. The limited storage capacity of the pathology laboratories restricted the duration of the study period. Therefore, there was a potential that some cases were missed. Also, the limited demographic and clinical variables in the pathology reports hindered the detailed clinical investigation of the gynecological diseases involved in the study.

In conclusion, this study highlights the low prevalence of hysterectomy among women in the Gharbiah region of Egypt and confirmed the low incidence of uterine cancer in this population, ${ }^{38}$ eliminating the clinical impression that the low incidence of uterine cancer is due to high rate of hysterectomy. Future studies should investigate the clinical and demographic factors related to hysterectomy in this population for optimizing medical care and setting guidelines for practice. Additional research is needed to compare the indication of hysterectomy in this population to populations in other developing countries. With the high and increasing rates of obesity in this population, investigating the potential increase in hysterectomy would be an interesting research topic.

\section{Acknowledgments}

None.

\section{Author contributions:}

Conceptualization: S. A., A. S., J.M., R. C., S. R.,

Methodology: S. A., A. S., J. M.,

Software: S. A., J. M.

Validation: S. A., A. H., I. S., M. R.,

Formal Analysis: S. A., A. S., J. M., M.M.

Investigation: S. A., A. H., I. S., M. R., A. S.

Writing - original draft: S. A.

Writing - review \& editing: S. A., A. S., J.M., R. C., S. R., A. H., I. S., M. R., M.M.

Supervision: A. S.

\section{Funding}

None.

\section{Conflicts of interest}

The Authors declare that there is no conflict of interest.

\section{References}

1. Jemal A, Bray F, Center MM, et al. Global cancer statistics. CA Cancer J Clin. 2011;61(2):69-90.

2. Ferlay J, Soerjomataram I, Ervik M, et al. cancer incidence and mortality worldwide: IARC CancerBase No. 11. Lyon, France: International Agency for Research on Cancer. GLOBOCAN. 2015.

3. Freedman LS, Edwards B, Ries L, et al. Cancer incidence in four member countries (Cyprus, Egypt, Israel, and Jordan) of the Middle East Cancer Consortium (MECC) compared with US SEER 2006.

4. Sabbour SM. Epidemiological correlates of hysterectomy, a hospital based study 1995-1996 at Ain Shams Maternity Hospital. J Egypt Public Health Assoc. 2001;76(1-2):71-87 
5. Ministry of Health and Population [Egypt], El-Zanaty and Associates [Egypt], and ICF International. Egypt Demographic and Health Survey 2014. 2015th ed. Maryland, USA: Cairo, Egypt and Rockville; 2015.

6. American College of Obstetricians and Gynecologists. Choosing the route of hysterectomy for benign disease. ACOG Committee Opinion. 2009(444):1156-1158.

7. Carlson KJ, Nichols DH, Schiff I. Indications for hysterectomy. $N$ Engl J Med. 1993;328(12):856-860.

8. Hawkins J, Hudson C. Abdominal hysterectomy for benign conditions. Shaw's textbook of operative gynaecology. 4th edn. Scotland: Churchill Livingstone; 1977:146-175.

9. Merrill RM. Hysterectomy surveillance in the United States, 1997 through 2005. Med Sci Monit. 2008;14(1):CR24-CR31.

10. Stang A, Hawk H, Knowlton R, et al. Hysterectomy-corrected incidence rates of cervical and uterine cancers in Massachusetts, 1995 to 2010. Ann Epidemiol. 2014;24(11):849-854.

11. Lundholm C, Forsgren C, Johansson AL, et al. Hysterectomy on benign indications in Sweden 1987-2003: a nationwide trend analysis. Acta Obstet Gynecol Scand. 2009;88(1):52-58.

12. Cohen SL, Vitonis AF, Einarsson JI. Updated hysterectomy surveillance and factors associated with minimally invasive hysterectomy. JSLS. 2014;18(3):e2014.00096.

13. Whiteman MK, Hillis SD, Jamieson DJ, et al. Inpatient hysterectomy surveillance in the United States, 2000-2004. Obstet Gynecol. 2008;198(1):e1-e734.

14. Lykke R, Blaakær J, Ottesen B, et al. Hysterectomy in Denmark 1977-2011: changes in rate, indications, and hospitalization. European Journal of Obstetrics \& Gynecology and Reproductive Biology. 2013;171(2):333-338.

15. Sherman ME, Carreon JD, Lacey JV, et al. Impact of hysterectomy on endometrial carcinoma rates in the United States. J Natl Cancer Inst. 2005;97(22):1700-1702.

16. Siegel RL, Devesa SS, Cokkinides V, et al. State-level uterine corpus cancer incidence rates corrected for hysterectomy prevalence, 2004 to 2008. Cancer Epidemiol Biomarkers Prev. 2013;22(1):25-31.

17. Rodriguez AM, Schmeler KM, Kuo YF. Disparities in endometrial cancer outcomes between non-Hispanic White and Hispanic women. Gynecol Oncol. 2014;135(3):525-533.

18. Redburn JC, Murphy MF. Hysterectomy prevalence and adjusted cervical and uterine cancer rates in England and Wales. BJOG. 2001;108(4):388-395.

19. Stang A, Merrill RM, Kuss O. Prevalence-corrected hysterectomy rates by age and indication in Germany 2005-2006. Arch Gynecol Obstet. 2012;286(5):1193-1200.

20. Luoto R, Rutanen E, Kaprio J. Five gynecologic diagnoses associated with hysterectomy - Trends in incidence of hospitalizations in Finland, 1971-1986. Maturitas. 1994;19(2):141-152.

21. The central agency for public mobilization \& statistics (CAPMAS). Statistical year book: CAPMAS; 2006.
22. Taylor R, Rushworth RL. Hysterectomy fractions in New South Wales, 1971-2006. Aust N Z J Public Health. 1998;22(7):759-764.

23. Alshahrani S, Soliman A, Hablas A, Ramadan M, Meza J, Remmenga $\mathrm{S}$, et al. Changes in Uterine Cancer Incidence Rates in Egypt. Obstetrics and Gynecology International in press. Obstet Gynecol Int. 2018;2018:3632067.

24. Materia E, Rossi L, Spadea T, et al. Hysterectomy and socioeconomic position in Rome, Italy. J Epidemiol Community Health. 2002;56(6):461465.

25. McPherson K, Wennberg JE, Hovind OB, et al. Small-area variations in the use of common surgical procedures: an international comparison of New England, England, and Norway. N Engl JMed. 1982;307(21):1310 1314.

26. Nordberg E, Holmberg S, Kiugu S. Rates of major surgery by age and sex in a rural district in Kenya. Ann Trop Med Parasitol. 1996;90(2):213221.

27. Keshavarz H, Hillis SD, Kieke BA, et al. Hysterectomy surveillanceUnited States, 1994-1999. MMWr cDc Surveill Summ. 2002;51(SS05):18 .

28. Desai S, Sinha T, Mahal A. Prevalence of hysterectomy among rural and urban women with and without health insurance in Gujarat, India. Reprod Health Matters. 2011;19(37):42-51.

29. Howe HL. Age-specific hysterectomy and oophorectomy prevalence rates and the risks for cancer of the reproductive system. Am J Public Health. 1984;74(6):560-563.

30. Jamison PM, Noone AM, Ries LA, et al. Trends in endometrial cancer incidence by race and histology with a correction for the prevalence of hysterectomy, SEER 1992 to 2008. Cancer Epidemiol Biomarkers Prev. 2013;22(2):233-241.

31. Stang A. Impact of hysterectomy on the age-specific incidence of cervical and uterine cancer in Germany and other countries. Eur J Public Health. 2013;23(5):879-883.

32. Domenighetti G, Luraschi P, Marazzi A. Hysterectomy and sex of the gynecologist. N Engl J Med. 1985;313(23):1482.

33. Domenighetti G, Casabianca A. Rate of hysterectomy is lower among female doctors and lawyers' wives. BMJ. 1997;314(7091):1417.

34. Domenighetti G, Luraschi P, Casabianca A, et al. Effect of information campaign by the mass media on hysterectomy rates. Lancet. 1988;2(8626-8627):1470-1473.

35. Elson J. Am I Still a woman?: Hysterectomy and gender identity. Temple University Press; 2004.

36. Serour GI. Medical and socio-cultural aspects of infertility in the Middle East. ESHRE Monographs. 2008;2008(1):34-41.

37. Settnes A, Jorgensen T, Lange AP. Hysterectomy in Danish women: weight-related factors, psychologic factors, and life-style variables. Obstet Gynecol. 1996;88(1):99-105.

38. Gimbel H, Settnes A, Tabor A. Hysterectomy on benign indication in Denmark 1988-1998. A register based trend analysis. Acta Obstet Gynecol Scand. 2001;80(3):267-272. 